\title{
Power Management Strategy for Active Power Sharing in Hydro/PV/Battery Hybrid Energy System
}

\author{
Sweeka Meshram, Ganga Agnihotri, and Sushma Gupta \\ Department of Electrical Engineering, MANIT, Bhopal, Madhya Pradesh 462051, India \\ Correspondence should be addressed to Sweeka Meshram; sweekam@gmail.com
}

Received 23 September 2013; Accepted 24 October 2013

Academic Editors: K. Ariyur and Y.-C. Song

Copyright ( 2013 Sweeka Meshram et al. This is an open access article distributed under the Creative Commons Attribution License, which permits unrestricted use, distribution, and reproduction in any medium, provided the original work is properly cited.

Simulation and modeling of standalone DC linked hydro/PV/battery hybrid energy system (HES) and power management strategy (PMS) for identifying the active power sharing have been done. The performance analysis of the proposed HES and its power management strategy has been done using the simulink toolboxes of MATLAB software. The proposed system consists of $10 \mathrm{~kW}$ PV system, $7.5 \mathrm{~kW}$ hydro system, battery, and power condition unit. In some remote/rural areas, it is very difficult to satisfy the demand of electrical power throughout the year with the power grid. In such areas, the power requirement can be fulfilled by renewable energy system such as hydro or PV system. Either the hydro system or PV system is not capable of supplying power requirement throughout the year as both systems are intermittent. Hence, the judicious combination of hydro and PV system has been modeled for electrification. The power management strategy is modeled to manage the power flow of the energy systems and battery to fulfill the load demand. The presented results clearly show that the proposed HES and its control strategy are suitable for implementation in remote/rural areas.

\section{Introduction}

Electrification of remote/isolated areas (where grid accessibility is not possible) may be possible by harnessing the renewable energy sources presented in the particular areas. Among these renewable energy sources, hydro and solar energy sources are more promising for electricity generation. The hydro and PV system are gaining the momentum of researchers for electrification in remote/rural areas.

Either standalone hydro system or PV system is not sufficient to fulfill the power requirement throughout the year. Therefore, for getting the optimal results by combining the advantages of hydro and solar energy sources, PV/hydro hybrid system has been analyzed and also installed [1-3].

The geographical and climatic condition affects the performance of the hybrid system. Therefore, a backup is necessary in the case when one of the energy sources is not available or the power generated by the hybrid system is not capable of fulfilling the power demand. To ensure the continuous power supply and to take care of intermittent nature of energy systems, diesel generator can be integrated to overcome the problem [4, 5]. Economic analysis and cost optimization of such system have been done to ensure the existence of the system [6, 7]. The additions of diesel generator are advantageous over the pure renewable energy system but also have some major problems such as diesel generator needs fossil fuel and surplus energy during the good season cannot be stored and provides short-term storage [8]. To overcome these problems, recently, the hydrogen storage system is taking the place of diesel generator and such power generating systems have been designed and developed for rural and coastal residential applications. It can be concluded that the hydrogen-based system can become a favorable system without aid from the grid system and bring advantage from technical and economic point of view and is also suitable to be applied in the rural and coastal residential application $[9,10]$.

The integration of the diesel generator or hydrogen storage system adds the cost and complexity of the system. The combination of the hybrid system with battery and efficient power management system (PMS) makes the best use of the advantages of each power generating system $[11,12]$. 


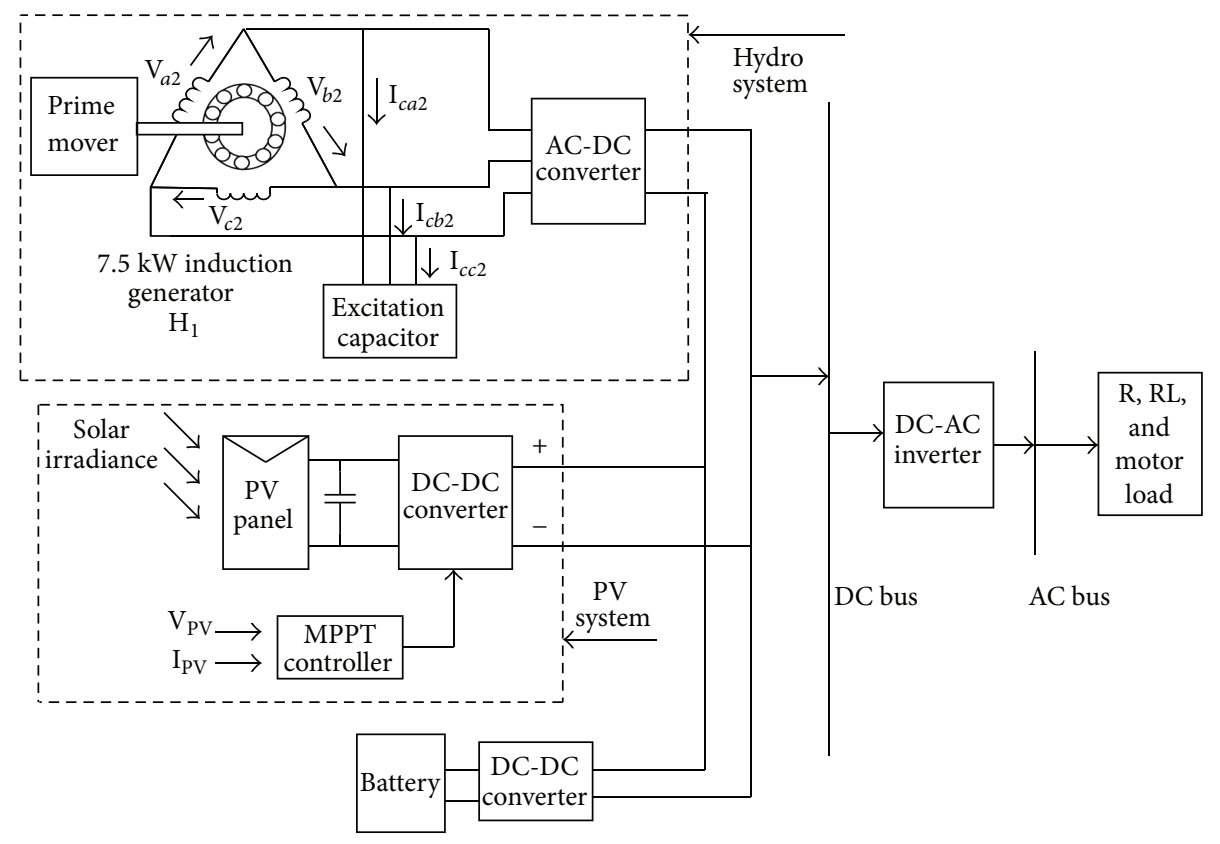

FIGURE 1: Schematic diagram of the hybrid energy system.

In this paper, a hydro/PV/battery-based hybrid energy system (HES) is proposed for electrification of remote/rural areas. The PV system is capable of generating $10 \mathrm{~kW}$ power only in sunny days. Therefore, a $7.5 \mathrm{~kW}$ hydro system is integrated with the PV system to supply the power throughout the year. But the PV power is variable and the PV/hydro system is also not able to feed the required load demand. Hence, a $200 \mathrm{~V}, 13.5 \mathrm{Ah}$ lead acid battery is also integrated to make the efficient HES system. The power management system (PMS) is developed to control the flow of energy of individual power generating system and battery. The PMS is designed such that the use of battery is as low as possible. The hydro/PV hybrid system works as a dominant system and battery as a backup.

\section{System Description}

Figure 1 shows the schematic diagram of the standalone PV/hydro hybrid energy system. There are three main parts of the HES: hydro system, PV system, and battery. The hydro system is configured by hydro turbine driven self-excited induction generator (SEIG) with initial excitation requirement fulfilled by the capacitor bank and an AC/DC converter. The PV system consists of PV array and DC/DC converter. the maximum power point tracking (MPPT) controller is employed to enhance the system efficiency and to control the DC/DC converter.

In the HES, the renewable hydro and PV system are considered as a primary source for supplying load demand and battery is used as a backup and storage system. The HES is developed to be implemented in the remote/isolated areas; hence, if HES generated power is inefficient to sustain the load, then battery power will be delivered to balance the power demand.
The control of all the renewable systems and battery is provided through the independent controllers such as MPPT controller. To interface hydro/PV system and battery, the voltage levels must be the same. Hence, DC/DC converters are used in the HES system to link the common DC voltage of the renewable systems.

\section{System Component Modeling}

To investigate the performance of the HES system and its PMS, mathematical models of its main components have been developed and simulated using the MATLAB simulink toolbox. The mathematical models for hydro system, PV system, and battery have been developed in this section.

3.1. Hydro System. A $7.5 \mathrm{~kW}$ hydro system uses SEIG and capacitor bank. The model equation of the SEIG can be represented as

$$
[v]=[R][i]+[L] p[i]+\omega_{g}[G][i] .
$$

The current derivative (i.e., $p[i]=d i / d t$ ) can be expressed from (1) as

$$
p[i]=[L]^{-1}\left\{[v]-[R][i]-\omega_{g}[G][i]\right\},
$$

where

$$
\begin{gathered}
{[v]=\left[\begin{array}{llll}
v_{d s} & v_{q s} & v_{d r} & v_{q r}
\end{array}\right]^{T},} \\
{[i]=\left[\begin{array}{llll}
i_{d s} & i_{q s} & i_{d r} & i_{q r}
\end{array}\right]^{T},} \\
{[R]=\left[\begin{array}{cccc}
R_{s} & 0 & 0 & 0 \\
0 & R_{s} & 0 & 0 \\
0 & 0 & R_{r} & 0 \\
0 & 0 & 0 & R_{r}
\end{array}\right],}
\end{gathered}
$$




$$
\begin{gathered}
{[L]=\left[\begin{array}{cccc}
L_{l s}+L_{m} & 0 & L_{m} & 0 \\
0 & L_{l s}+L_{m} & 0 & L_{m} \\
L_{m} & 0 & L_{l r}+L_{m} & 0 \\
0 & L_{m} & 0 & L_{l r}+L_{m}
\end{array}\right],} \\
{[0]=\left[\begin{array}{cccc}
0 & 0 & 0 & 0 \\
0 & 0 & 0 & 0 \\
0 & -L_{m} & 0 & L_{l r}+L_{m} \\
L_{m} & 0 & L_{l r}+L_{m} & 0
\end{array}\right]}
\end{gathered}
$$

$v_{d r}$ and $v_{q r}$ will be zero when the rotor terminals of the SEIGs are shorted.

The developed electromagnetic torque $\left(T_{e}\right)$ of the SEIG is as follows:

$$
T_{e}=\frac{3 P}{4} L_{m}\left(i_{q s} i_{d r}-i_{d s} i_{q r}\right) .
$$

The electromechanical torque of the SEIG is modeled as

$$
T_{\text {shaft }}=T_{e}+J\left(\frac{2}{P}\right) \frac{d \omega_{g}}{d t} .
$$

The derivative of rotor speed $\left(d \omega_{g} / d t\right)$ can be derived from (5) as follows:

$$
\frac{d \omega_{g}}{d t}=\frac{(P / 2)\left(T_{\text {shaft }}-T_{e}\right)}{J} .
$$

The torque ( $\left.T_{\text {shaft }}\right)$ is transmitted to shaft of SEIG to the prime mover.

The capacitor bank used for initial excitation of the SEIG can be mathematically modeled as

$$
\begin{aligned}
& \frac{d V_{s q}}{d t}=\frac{i_{c q}}{C_{q}}, \\
& \frac{d V_{s d}}{d t}=\frac{i_{c d}}{C_{d}},
\end{aligned}
$$

where $C_{d}$ and $C_{q}$ are the $d$ and $q$ axis component of the 3- $\phi$ capacitor bank connected at the stator terminal of the SEIG.

3.2. PV System Characteristics and Modeling. PV system consists of PV array and DC/DC converter. PV array is the series and parallel combination of many PV cells to get the desired output voltage and current. The PV array exhibits the nonlinear VI characteristic. In this paper, SunPower ${ }^{\mathrm{TH}}$ 305 solar panel is used. The panel utilizes the 96 SunPower all-back contact monocrystalline solar cells. The PV system is modeled to integrate the hydro system and battery to fulfill the power requirement in the remote/isolated areas. The PV system with nonlinear VI characteristic can be mathematically modeled as

$$
V_{\mathrm{PV}}=\frac{N_{S} A k T}{q} \ln \left[\frac{I_{\mathrm{sc}}-I_{\mathrm{PV}}+N_{P}}{N_{P} I_{D}}\right]-\frac{N_{S}}{N_{P}} R_{S} I_{\mathrm{PV}},
$$

where $V_{\mathrm{PV}}$ is the output voltage of the PV panel in $\mathrm{V}, I_{\mathrm{PV}}$ is the output current of the PV panel in A, $A$ is the ideality factor
(2.46), $k$ is Boltzmann's constant $\left(1.38 \times 10^{-23} \mathrm{~J} / \mathrm{K}\right), q$ is charge of electron $\left(1.602 \times 10^{-19} \mathrm{C}\right), T$ is PV cell temperature in $\mathrm{K}$, $N_{S}$ is the number of series connected PV modules, $N_{P}$ is the number of parallel connected PV string, $I_{\mathrm{sc}}$ is short circuit current of $\mathrm{PV}$ cell in $\mathrm{A}, I_{D}$ is reverse saturation current of cell $(0.0002 \mathrm{~A})$, and $R_{S}$ is series resistance of PV cell $(0.001 \Omega)$.

3.3. Lead Acid Battery. In this section, the mathematical modeling of the rechargeable lead acid battery has been done, which is used for simulating the hybrid system. A lead acid battery is modeled as follows:

$$
V_{B}=V_{\mathrm{OCB}}-R_{B} I_{B} .
$$

During discharge mode of battery $\left(i^{*}>0\right)$,

$$
V_{\mathrm{OCB}}=V_{0}-k \frac{Q}{Q-i t} \cdot i^{*}-k \frac{Q}{Q-i t} i t+L^{-1}\left\{\frac{\exp (s)}{\operatorname{sel}(s)} \cdot 0\right\} .
$$

During charge mode of the battery $\left(i^{*}<0\right)$,

$$
\begin{aligned}
V_{\mathrm{OCB}}= & V_{0}-k \frac{Q}{i t+0.1 Q} \cdot i^{*}-k \frac{Q}{Q-i t} i t \\
& +L^{-1}\left\{\frac{\exp (s)}{\operatorname{sel}(s)} \cdot \frac{1}{s}\right\},
\end{aligned}
$$

where $V_{B}$ is the battery voltage in $\mathrm{V}, V_{\mathrm{OCB}}$ is the open circuit voltage in $\mathrm{V}, R_{B}$ is the internal resistance of the battery in $\Omega$, $I_{B}$ is the battery current in $\mathrm{A}, V_{0}$ is the constant voltage of the battery in $\mathrm{V}, k$ is the polarization constant in $\mathrm{Ah}^{-1}, \mathrm{Q}$ is the maximum battery capacity in $\mathrm{Ah}$, it is the extracted capacity in $\mathrm{Ah}, i^{*}$ is the low frequency dynamics in $\mathrm{A}, \exp (s)$ is the exponential zone dynamics in $\mathrm{V}$, and $\operatorname{sel}(s)$ is for representing the battery mode. For sel $(s)=0$, battery will be in discharge mode, and for $\operatorname{sel}(s)=1$, battery will be in charge mode.

\subsection{Power Conditioning Unit}

3.4.1. DC-DC Converter. The PV system uses the DC-DC converter to employ the MPPT to get the maximum efficiency from the PV system with the variation in the temperature and solar irradiance. The output of the PV array is very less, therefore it is required to boost their voltage. This feature is also provided by the DC-DC boost converter. Equation (12) describes the output voltage as a function of PV voltage and duty cycle as follows:

$$
V_{\mathrm{DC}}=\frac{1}{1-D} V_{\mathrm{PV}} .
$$

The duty cycle $D$ is controlled by the MPPT controller.

3.4.2. DC-AC Inverter. The DC-AC inverter accepts the regulated voltage from the $\mathrm{DC}$ bus and converts it into an $\mathrm{AC}$ voltage. The inverter AC voltage $\left(V_{\text {inv }}\right)$ and power $\left(P_{\text {inv }}\right)$ can be given as

$$
\begin{gathered}
V_{\mathrm{inv}}=M \cdot V_{\mathrm{DC}} \angle \delta \quad 0<M<1 \\
P_{\mathrm{inv}}=\frac{M \cdot V_{\mathrm{DC}} \cdot V_{L}}{X} \sin (\delta) .
\end{gathered}
$$




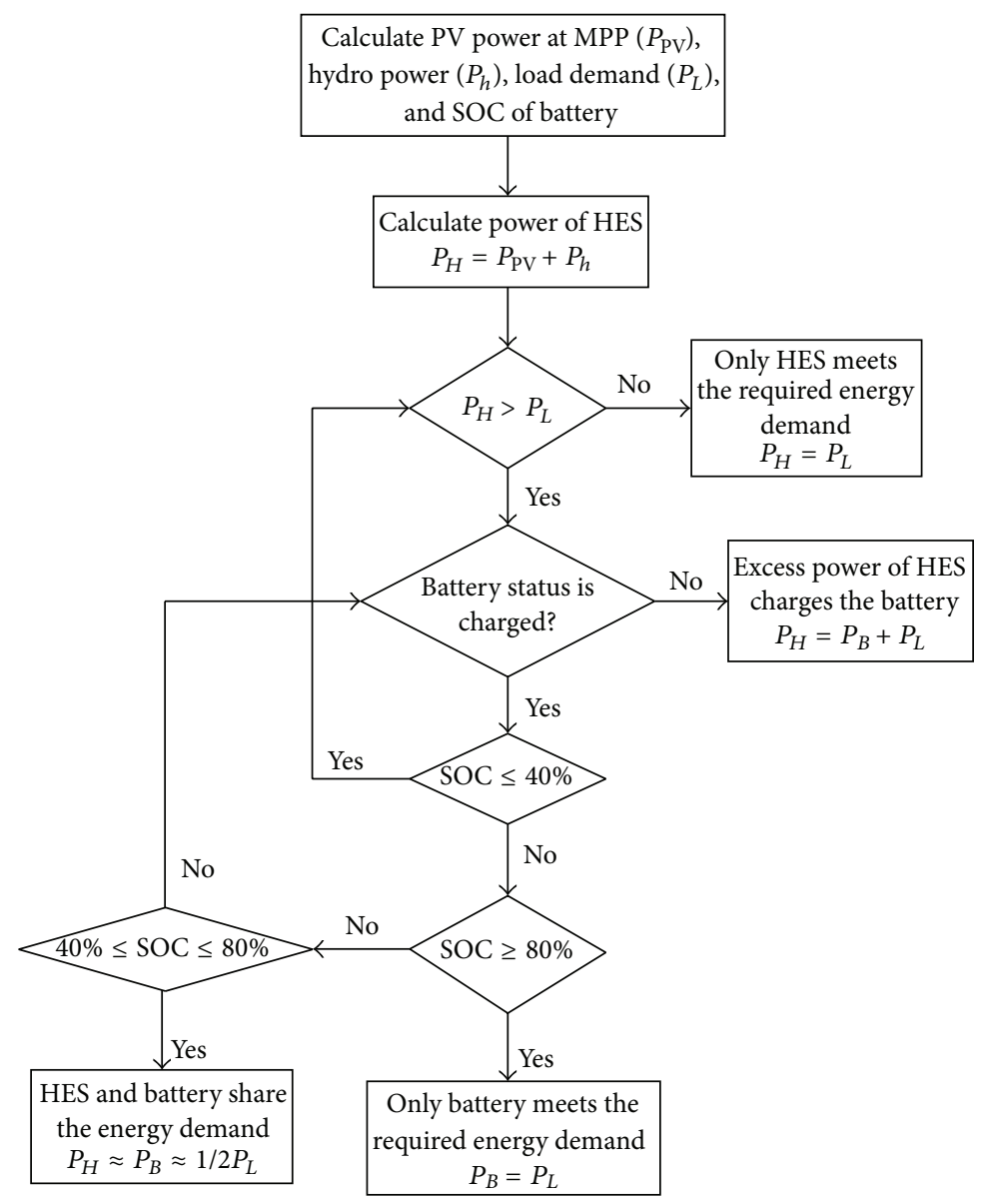

FIGURE 2: Flow chart for the PMS.

The $M$ and $\delta$ control the inverter output voltage $V_{\text {inv }}$ and the active power flow $\left(P_{\text {inv }}\right)$ from the HES system as per load demand.

\section{Power Management System}

The hybrid power generation system requires a power management system (PMS), which controls the proper active power flow from and to the battery storage system. The PMS is used for controlling the power distribution among the hydro system, PV system, and battery.

Figure 2 depicts the flow chart for the PMS for controlling the power flow among the renewable systems. When the total power generation $\left(P_{H}\right)$ of the hybrid system (i.e., combination of hydro and PV system) is higher than the load demand $\left(P_{L}\right)$, then the excess power is used to charge the battery and to feed the power to the load of selected area. As the hydro and PV systems are intermittent in nature, the variation in the power generation will be according to seasonal variation. Hence, it is not necessary that the HES may fulfill the required load demand. When $P_{H}$ is not able to fulfill $P_{L}$, the battery is allowed to share the required real power. The power management of the HES depends on the SOC of the battery; correspondingly, the battery can be charged or discharged.
In order to obtain efficient power distribution among the hydro system, PV system, and battery, the battery should operate in the high efficiency region and battery SOC should be maintained at a reasonable level that is between $40 \%$ and $80 \%$.

\section{Results and Discussion}

The proposed hybrid energy system and its control strategy are developed and simulated in MATLAB software and the behavior of the system is observed under different operating conditions. The solar irradiance (Ir) and the load profile (PL) used for testing the proposed system are shown in Figures 3(a) and 3(b), respectively. For hydro system, the stored water drives the prime mover of the SEIG with constant speed to generate the $7.5 \mathrm{~kW}$ power.

The $10 \mathrm{~kW}$ PV panel is used for simulating the hybrid system for remote areas. As per solar irradiance (Ir), the power generated by the PV panel $\left(P_{\mathrm{PV}}\right)$ varies from $5.78 \mathrm{~kW}$ to $10.68 \mathrm{~kW}$. Figure $4(\mathrm{a})$ shows the power generation $\left(P_{\mathrm{PV}}\right)$ by the PV panel. The generated voltage of the PV panel will also vary in accordance with the solar irradiance as shown in Figure 4(b). The MPPT controller is employed to get the maximum efficiency of the PV system. Figure 4(c) shows the variation in duty cycle $(D)$ of the DC-DC converter. 


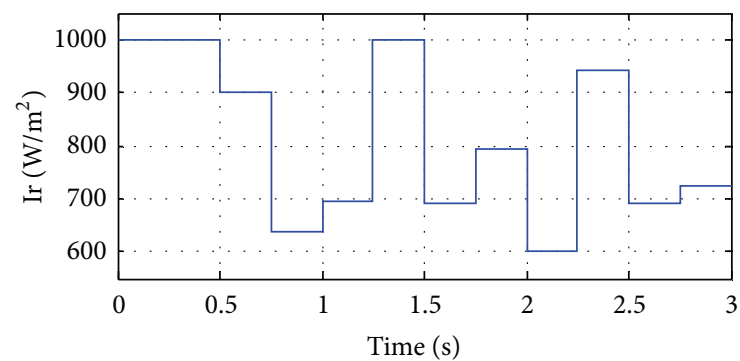

(a)

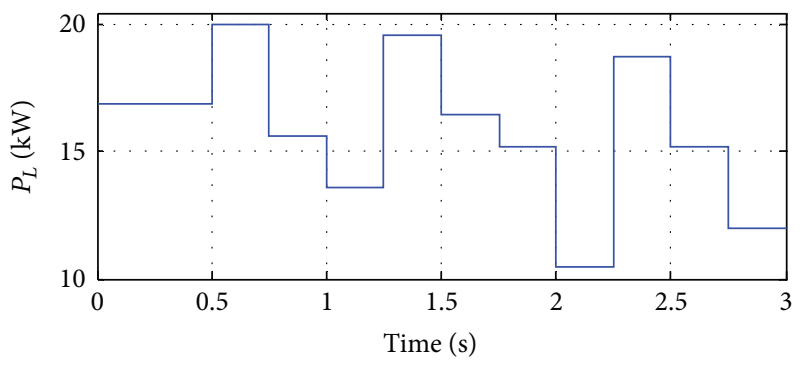

(b)

FIGURE 3: (a) Solar irradiance in $\mathrm{W} / \mathrm{m}^{2}$; (b) required power demand in $\mathrm{kW}$.

Figure 5 shows the combined power generation of the hydro and PV system $\left(P_{H}\right)$. The PMS controls the charging/discharging of the battery bank. When the $P_{H}$ is less than the $P_{L}$, the parallel connected hydro and PV system will fulfill the load demand, and when the $P_{H}$ is greater than the $P_{L}$, battery will also share the power.

Before $0.5 \mathrm{sec}$, the $P_{H}$ is capable of fulfilling the required load demand. Hence, the battery will charge only. During period $0.5-0.75$ seconds, the load demand is $20 \mathrm{~kW}$ and the $P_{H}$ is $16.54 \mathrm{~kW}$. In that duration, the battery is sharing the power to compensate the anticipated load and discharges the stored power. During 0.75-0.1 seconds, again the load demand $P_{L}$ is greater than the $P_{H}$, therefore, the battery is in discharge mode. Figures $6(\mathrm{a})$ and $6(\mathrm{~b})$ show the power shared by the battery and current through the battery, respectively. Figure $6(\mathrm{c})$ shows the $\%$ SOC of the battery and shows the battery charging and discharging.

Figures 7(a) and 7(b) show the waveform of load current for the resistive load of about $5 \mathrm{~kW}$ and RL load of about $2.5 \mathrm{~kW}$ with 0.8 lagging power factor. For clear vision, one phase with the time range from $0.8 \mathrm{sec}$ to $1.2 \mathrm{sec}$ is shown. Figures $7(\mathrm{c})$ and $7(\mathrm{~d})$ show the stator current and speed of $3.7 \mathrm{~kW}, 415 \mathrm{~V}, 1500 \mathrm{rpm}$, and $50 \mathrm{~Hz}$ IM load, respectively.

\section{Conclusion}

In remote/isolated areas, where grid accessibility is not possible, the electrical power requirement can be fulfilled by harnessing the renewable energy sources. For such areas, standalone hydro/PV/battery hybrid system has been modeled and simulated using the MATLAB simulink toolboxes. To improve the power quality of the hybrid system and to

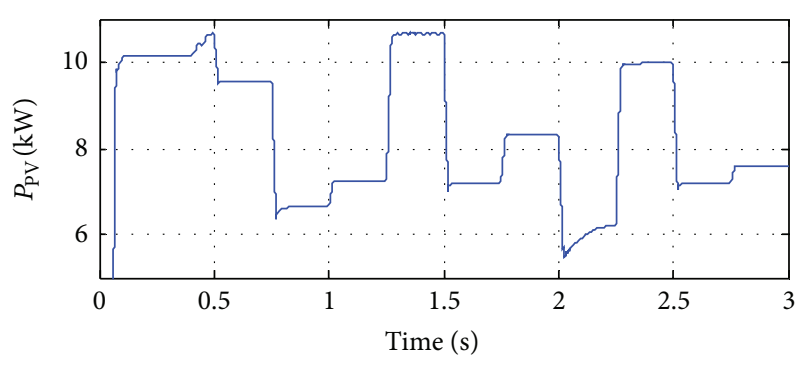

(a)

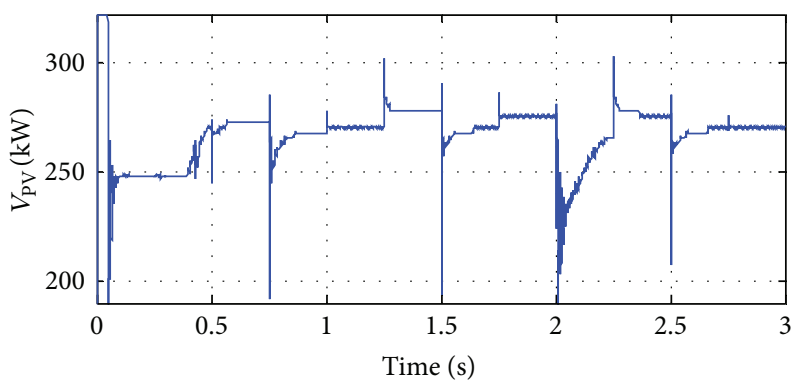

(b)

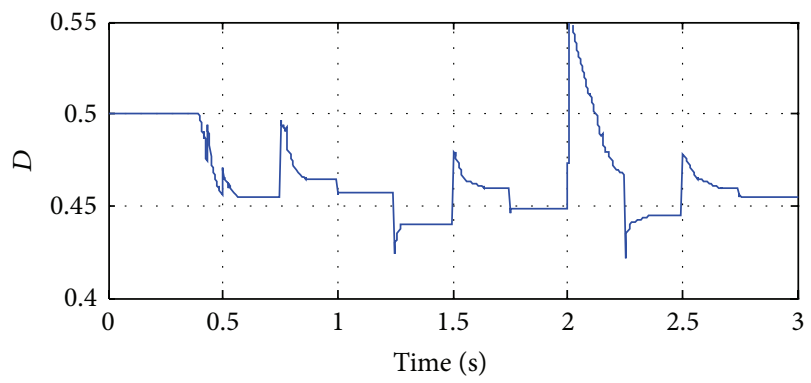

(c)

FIgURE 4: (a) Output power of PV panel with respect to solar irradiance. (b) PV panel output voltage. (c) Duty cycle of the DCDC converter to get MPP.

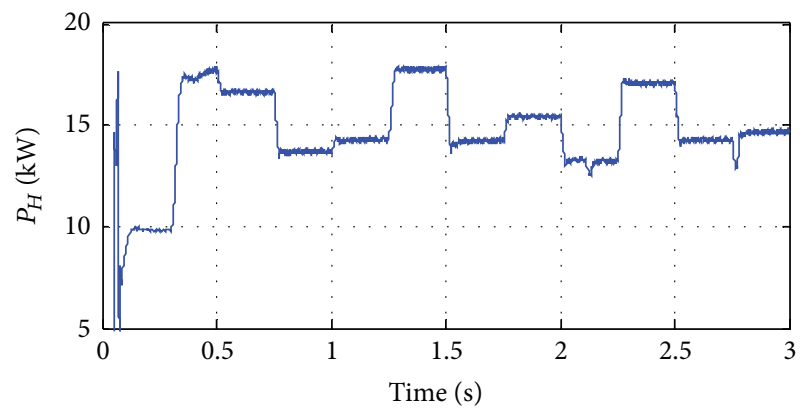

FIgURE 5: Total power generation of hydro and PV system.

control the power distribution among the power generating systems, an energy management system has been developed. The proposed system is tested under the resistive, RL, and induction motor (IM) load. The demonstrated results show that the proposed system can fulfill the power requirement of remote areas and the control strategy can supervise efficiently and maintain the battery SOC within the specified region. 


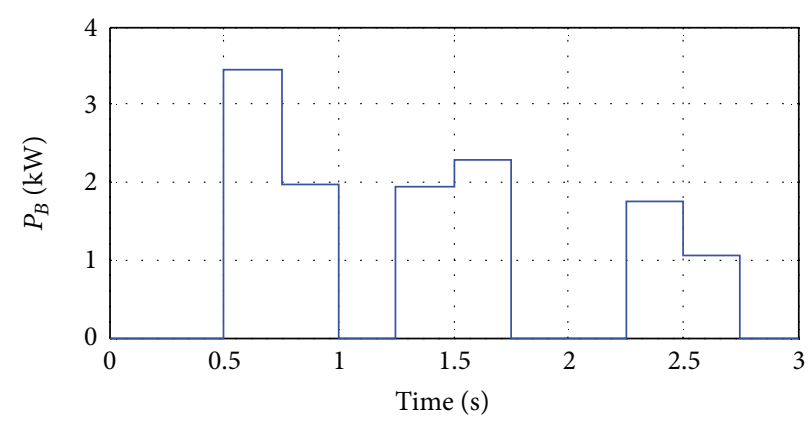

(a)

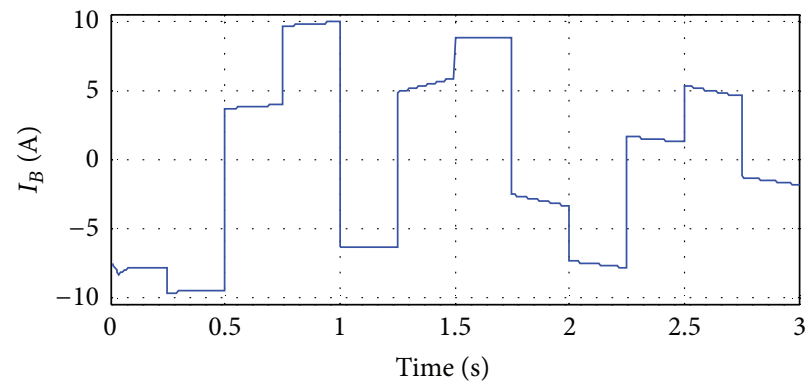

(b)

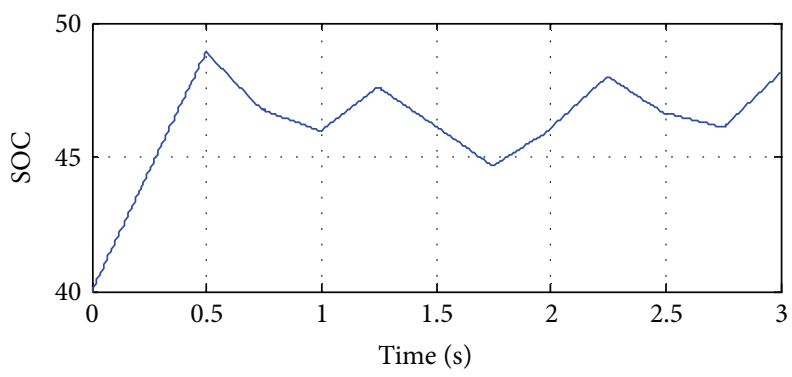

(c)

FIgURE 6: (a) Power met by the battery bank. (b) Current of the battery during charging/discharging. (c) Battery \% SOC.

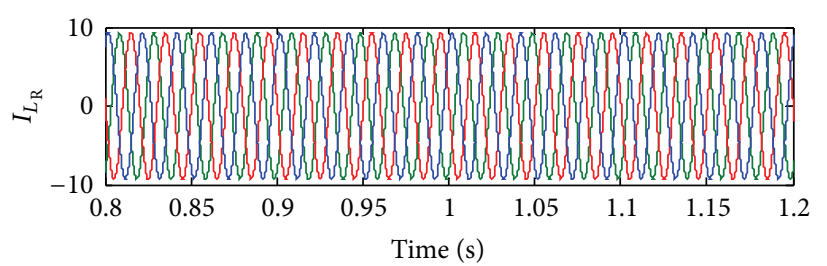

(a)

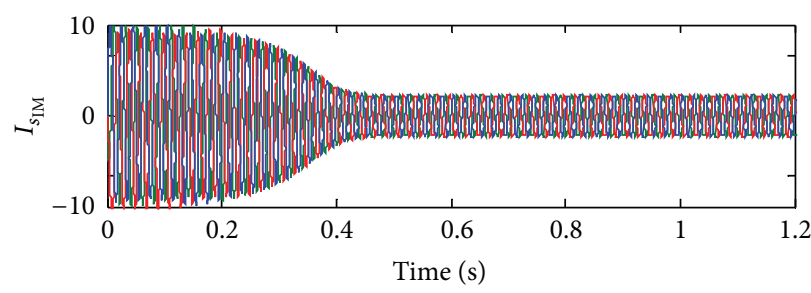

(c)

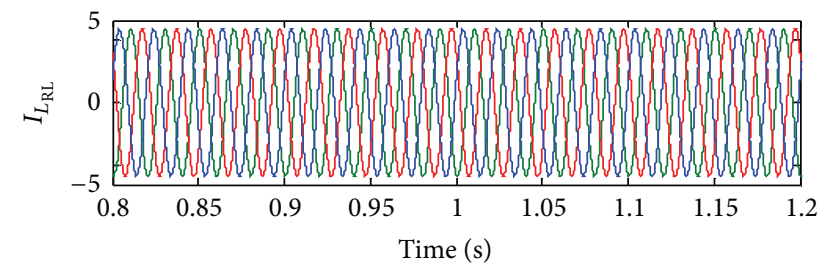

(b)

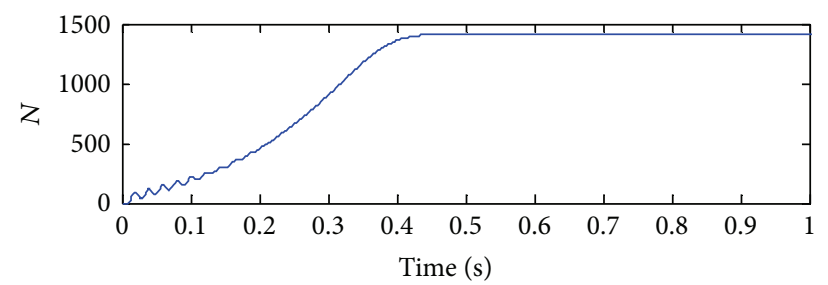

(d)

FIgure 7: (a) Current through the linear R load. (b) Current through the linear RL load. (c) Current through the IM load. (d) Speed of the IM.

\section{Appendix}

(a) The parameters of $7.5 \mathrm{~kW}, 415 \mathrm{~V}, 50 \mathrm{~Hz}, \Delta$-connected, 4-pole induction machine:

$$
\begin{aligned}
& R_{s}=1 \Omega, R_{r}=0.77 \Omega, \\
& X_{l r}=X_{l s}=1.5 \Omega, J=0.1384{\mathrm{~kg}-\mathrm{m}^{2}}^{2} \\
& L_{m}=0.134 \mathrm{H}\left(I_{m}<3.16\right), \\
& L_{m}=9 e-5 I_{m}^{2}-0.0087 I_{m}-0.1643\left(3.16<I_{m}<\right. \\
& 12.72), \\
& L_{m}=0.068 \mathrm{H}\left(I_{m}>12.72\right) .
\end{aligned}
$$

(b) Prime mover characteristics:

$$
\begin{aligned}
& T_{\text {sh }}=K_{1}-K_{2} \omega_{r}, \\
& K_{1}=1570, K_{2}=10 .
\end{aligned}
$$

(c) PV panel parameters:

module type: sunPower SPR-305-WHT, no. of cells $/$ module $=96$, no. of series connected modules/string $=5$, no. of parallel strings $=7$, 
module specification under STC:

$$
\begin{aligned}
& V_{\mathrm{oc}}=64.2, I_{\mathrm{sc}}=5.96, V_{\mathrm{mp}}=54.7, \text { and } \\
& I_{\mathrm{mp}}=5.58,
\end{aligned}
$$

model parameters for one module:

$$
\begin{aligned}
& R_{s}=0.038, R_{p}=993.5, I_{\mathrm{sat}}=3.1949 e-8, \\
& I_{\mathrm{ph}}=5.9602, A=1.3, \text { and } I_{D}=0.0002 .
\end{aligned}
$$

(d) Battery parameters:

type of battery = lead acid,

no. of battery connected in series $=3$,

nominal voltage $=200 \mathrm{~V}$,

maximum capacity of battery $=6.5 \mathrm{Ah}$, internal resistance $=0.382 \Omega$.

(e) Boost converter parameters:

$$
\begin{aligned}
& C_{B}=15 \mu \mathrm{F}, L_{B}=170 \mathrm{mH}, \\
& \text { switching freq. }=10 \mathrm{kHz} .
\end{aligned}
$$

\section{References}

[1] R. Muhida, A. Mostavan, W. Sujatmiko, M. Park, and K. Matsuura, "10 Years operation of a PV-micro-hydro hybrid system in Taratak, Indonesia," Solar Energy Materials and Solar Cells, vol. 67, no. 1-4, pp. 621-627, 2001.

[2] E. M. Nfah and J. M. Ngundam, "Feasibility of pico-hydro and photovoltaic hybrid power systems for remote villages in Cameroon," Renewable Energy, vol. 34, no. 6, pp. 1445-1450, 2009.

[3] J. Kenfack, F. P. Neirac, T. T. Tatietse, D. Mayer, M. Fogue, and A. Lejeune, "Microhydro-PV-hybrid system: sizing a small hydro-PV-hybrid system for rural electrification in developing countries," Renewable Energy, vol. 34, no. 10, pp. 2259-2263, 2009.

[4] D. Saheb-Koussa, M. Haddadi, and M. Belhamel, "Economic and technical study of a hybrid system (wind-photovoltaicdiesel) for rural electrification in Algeria," Applied Energy, vol. 86, no. 7-8, pp. 1024-1030, 2009.

[5] J. L. Bernal-Agustín and R. Dufo-López, "Simulation and optimization of stand-alone hybrid renewable energy systems," Renewable and Sustainable Energy Reviews, vol. 13, no. 8, pp. 2111-2118, 2009.

[6] R. Dufo-López, J. L. Bernal-Agustín, J. M. Yusta-Loyo et al., "Multi-objective optimization minimizing cost and life cycle emissions of stand-alone PV-wind-diesel systems with batteries storage," Applied Energy, vol. 88, no. 11, pp. 4033-4041, 2011.

[7] M. S. Ngan and C. W. Tan, "Assessment of economic viability for $\mathrm{PV} /$ wind/diesel hybrid energy system in southern Peninsular Malaysia," Renewable and Sustainable Energy Reviews, vol. 16, no. 1, pp. 634-647, 2012.

[8] P. C. Ghosh, B. Emonts, and D. Stolten, "Comparison of hydrogen storage with diesel-generator system in a PV-WEC hybrid system," Solar Energy, vol. 75, no. 3, pp. 187-198, 2003.

[9] M. Z. Ibrahim, R. Zailan, M. Ismail, and A. M. Muzathik, "Prefeasibility study of hybrid hydrogen based energy systems for coastal residential applications," Energy Research Journal, vol. 1, pp. 12-21, 2010.
[10] B. Panahandeh, J. Bard, A. Outzourhit, and D. Zejli, "Simulation of PV-wind-hybrid systems combined with hydrogen storage for rural electrification," International Journal of Hydrogen Energy, vol. 36, no. 6, pp. 4185-4197, 2011.

[11] K.-S. Jeong, W.-Y. Lee, and C.-S. Kim, "Energy management strategies of a fuel cell/battery hybrid system using fuzzy logics," Journal of Power Sources, vol. 145, no. 2, pp. 319-326, 2005.

[12] C. Wang and M. H. Nehrir, "Power management of a standalone wind/photovoltaic/fuel cell energy system," IEEE Transactions on Energy Conversion, vol. 23, no. 3, pp. 957-967, 2008. 

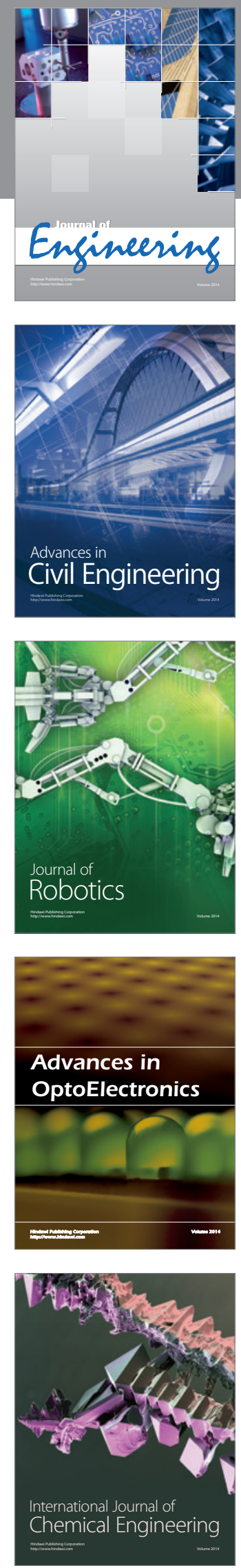

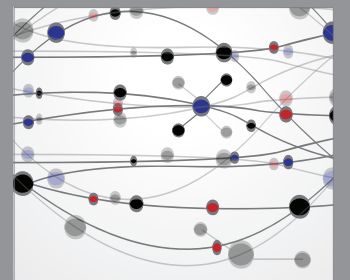

The Scientific World Journal
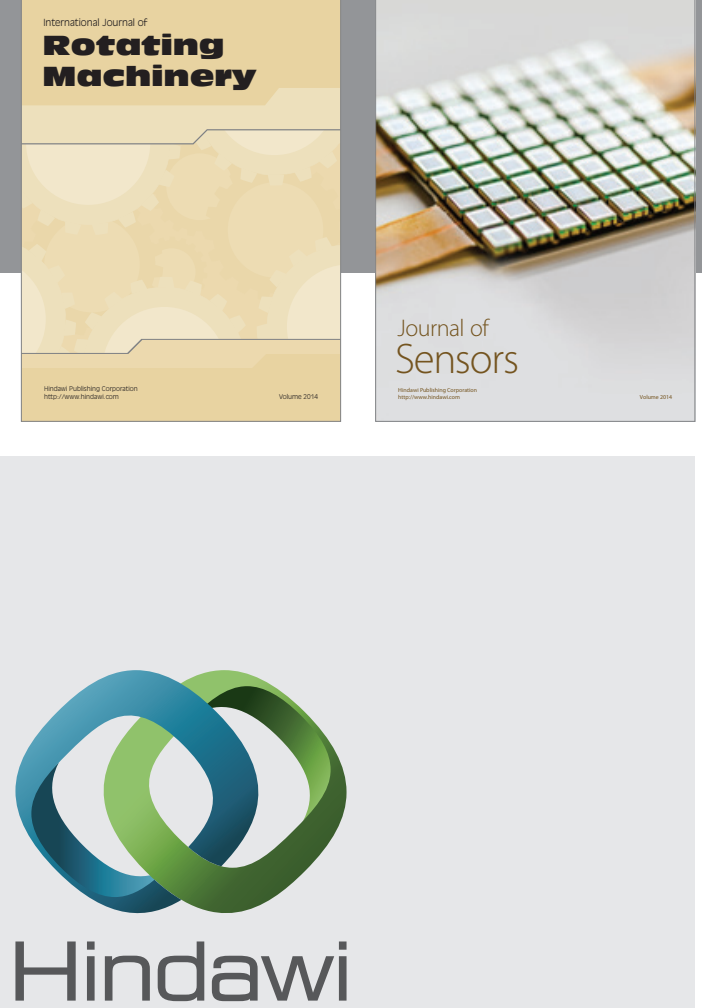

Submit your manuscripts at http://www.hindawi.com
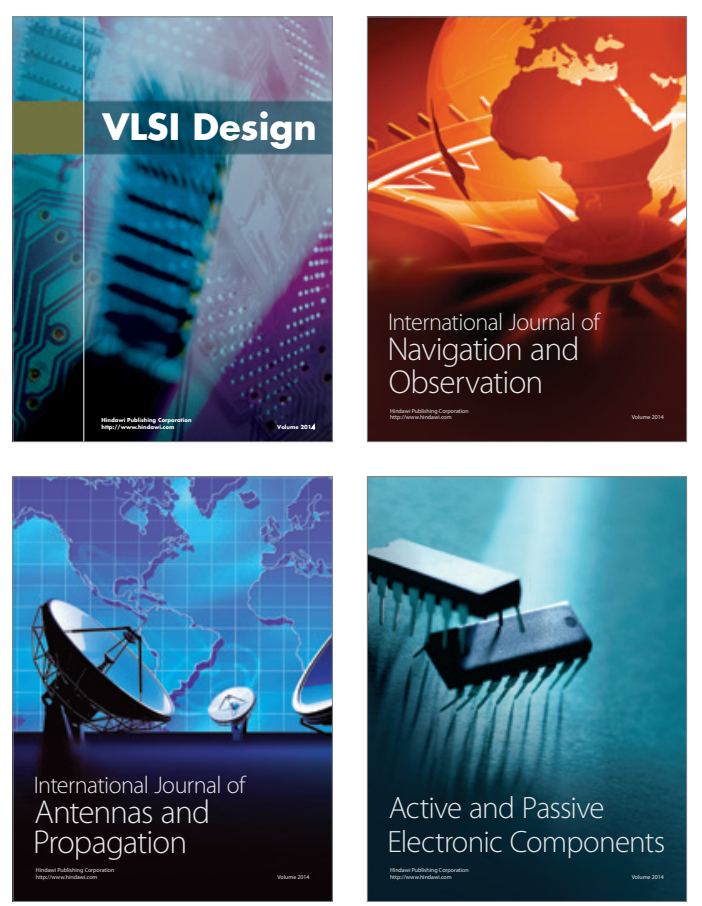
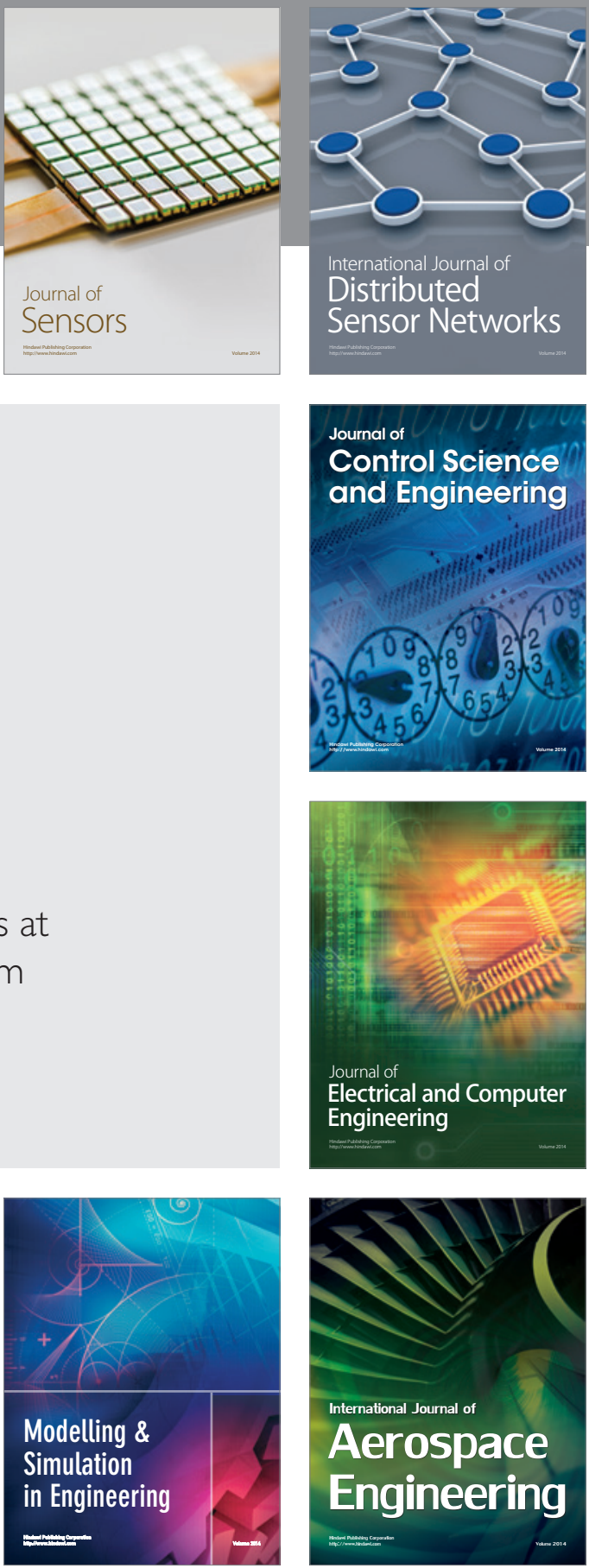

Journal of

Control Science

and Engineering
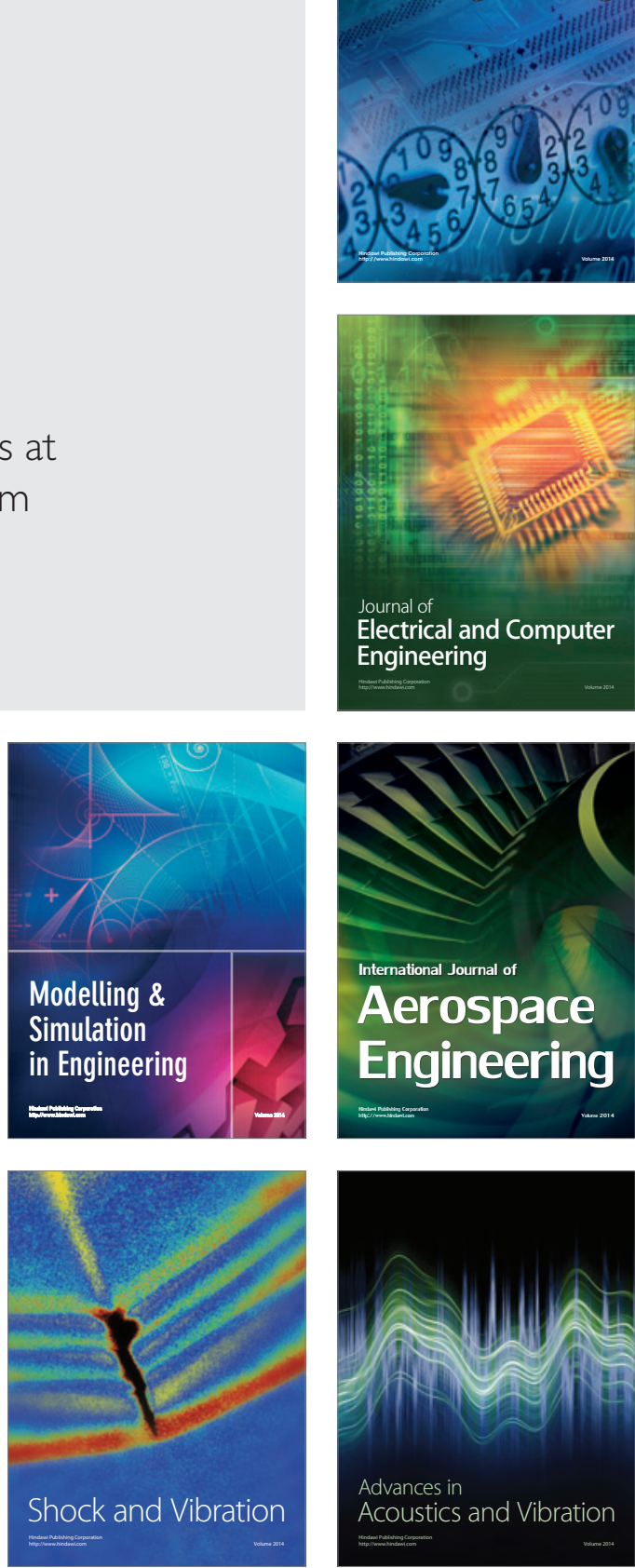